\title{
TRANSFORMASI INTERNASIONALISASI PERGURUAN TINGGI MENUJU WORLD CLASS UNIVERSITY
}

\section{Umi Zulfa}

\author{
(Dosen PAI Institut Agama Islam Alghozali Cilacap)
}

\begin{abstract}
World Class University (WCU) is phenomenon that recently becomes the aims of higher education in the world, including in Indonesia. For going to WCU, higher education can do the transformation throughout education internationatlization program. Internationaliztion of higher education itself is the integration process of international and intercultural dimention into the function of teaching, research and service from whole institution. Trought approach and several internationalization strategy, so bigher education can do transformation goes to WCU. Catching from these necessities, Indonesian government released policy about internationalization of higher education program.
\end{abstract}

Key words: World Class University, transformation, internationalization

\section{A. Pendahuluan}

Saat ini disadari atau tidak, kita telah masuk ke era globalisasi. Globalisasi sendiri merupakan suatu tatanan di mana dunia menjadi begitu terbuka dan transparan, sehingga ada kesan seolah-olah tak ada lagi batas negara. Kecenderungan global inilah yang oleh Kenichi Ohmae dalam Sufyarma (2004) disebut sebagai borderless world.

Sebenarnya adanya globalisasi dimulai dalam bidang informasi dan ekonomi, namun kemudian mempunyai implikasi yang sedemikian besar terhadap bidang-bidang lain, termasuk pendidikan. Pengaruh yang sedemikian kuat inilah yang memaksa setiap bangsa untuk mempersiapkan diri dengan sikap antisipasi atau bahkan beradaptasi dengan pengaruh globalisasi tersebut.

Satu kondisi yang diakibatkan oleh globalisasi adalah adanya hiperkompetisi, akselerasi suksesi revolusi Iptek, alienasi, stress, ketegangan antar kelompok, ketergantungan pada obat terlarang dan sebagainya, demikian yang diramalkan Gibson dalam Ahmadi (2005). Akibat inilah yang semestinya diperhitungkan dan diantisipasi sejak awal, agar tidak menimpa generasi muda bangsa yang sesungguhnya akan lebih banyak mengalami hidup dalam era globalisasi ini. Bentuk antisipasi dan adaptasi 
yang paling efektif adalah melalui proses pendidikan, karena sesungguhnya pendidikan bertugas untuk mempersiapkan peserta didik untuk hidup di masa depan.

Ketika dunia sudah berada dalam era globalisasi inilah, maka ada semacam tuntutan bago semua komponen yang ada di dunia ini untuk menyesuaikan dengan globalisasi. Tak terkecuali adalah dunia pendidikan, khususnya perguruan tinggi (PT). Berkaitan dengan hal tersebut, maka beberapa isu penting yang mesti dicermati oleh PT adalah internasionalisasi PT dan World Class University (WCU).

Menurut Prof.Dr.der Soz Gumilar R. Sumantri dalam Ghafur (2009), saat ini PT dihadapkan pada adanya tuntutan internasionalisasi dari era globalisasi. Tuntutan itu berkaitan dengan:

- Sifat keuniversalan ilmu pengetahuan (IP) yang tidak boleh dibatasi oleh sekat-sekat ruang dan waktu. IP adalah bahasa universal serta penghubung antarbudaya, antarbangsa, antar generasi dan antar zaman.

- Internasionalisasi sekaligus mendorong dan "memaksa" PT Indonesia untuk membangun mutu diri sendiri sesuai standar pendidikan dunia yang diukur oleh berbagai badan penjaminan mutu internasional dan akreditasi lintas batas negara.

- Internasionalisasi juga merangsang kalangan ilmuwan Indonesia untuk lebih extovert dengan membuka diri secara lebih luas ke komunitas dunia dengan mengumumkan karyakaryanya, terutama hasil penelitian, melalui jurnal-jurnal internasional.

- Untuk menunjukkan kepada dunia bahwa PT Indonesia tidak sekedar "jago kandang", melainkan mampu bersaing dengan berbagai PT lainnya di manca negara.

- Untuk turut mengangkat derajat bangsa melalui pendidikan tinggi yang bermutu dan terpercaya.

- Untuk turut mendorong adanya pengakuan dunia terhadap kualitas tenaga kerja lulusan PT Indonesia di pasar kerja internasional.

Disamping hal tersebut, globalisasi juga menuntut kesiapan setiap elemen kehidupan yang ingin tetap survive agar menyesuaikan dengan "apa yang dikehendaki oleh dunia". Jika setiap elemen kehidupan mampu menangkap apa yang apa yang dikehendaki masyarakat dunia, maka ia akan 
mampu memberikan kontribusi atas hal yang dibutuhkan dunia. Jika sudah demikian, maka elemen itu adalah elemen dari world class. Termasuk juga di dalamnya adalah PT. Jika PT menginginkan dirinya menjadi elemen WCU, maka PT tersebut harus mengetahui dan memberikan layanan dari apa yang semestinya dikehendaki dunia. Sedangkan salah satu jalan untuk menjadi WCU, PT tersebut harus terlebih dahulu melakukan strategi internasionalisasi PT.

Berdasarkan latar belakang di atas, maka tulisan ini akan melakukan pembahasan tentang "strategi internasionalisasi PT menuju World Class University". Untuk bisa membahas persoalan ini, maka rumusan masalahnya adalah: 1) bagaimana globalisasi mempengaruhi PT?, 2) bagaimana konsep internasionalisasi PT? Dan 3) bagaimana strategi internasionalisasi PT mampu mengantarjan PT ke WCU?

\section{B. Globalisasi Dan Implikasinya Bagi Perkembangan Perguruan Tinggi}

\section{Pengertian Globalisasi}

Sebelum memahami pengaruh globalisasi terhadap perkembangan PT, hal yang harus dilakukan terlebih dahulu adalah mengetahui dan memahami apa sesungguhnya globalisasi. Secara umum ada dua kutub yang bisa digunakan dalam memahmai apa globalisasi itu, yaitu bipolarisme konsep globalisasi (Khufad, 2009). Kutub pertama adalah kutub interdependensi dan kutub kedua adalah kutub dependensi. Kutub interdependensi digawangi oleh John Naisbit dan David Ricardo, sedangkan kutub dependensi tokohnya adalah Peter Drucker, Cohen dan Giddens.

- Masih dalam sumber yang sama, dijelaskan beberapa pandangan tentang globalisasi yang masuk dalam kutub interdepedensi:

a. Globalization is the process of increasing interdependence among countries and their citizents in all aspect.

b. Economic globalisation is the process of increasing economic interdependence among countries and theor citizens.

- Adapaun pandangan kutub dependensi adalah:

a. Globalization of economics. The rise of neo-capitalism (neo-liberalism)

b. Globalization of politics. The end of nation-state

c. Globalization of social relations. The stretching of social relations.

d. Globalizations $f$ culture. Homogenization: cultural imperalism.

\section{Implikasi Globalisasi Bagi Perkembangan PT}


Jika mengacu kepada konsep globalisasi sebagai proses peningkatan hubungan yang saling bergantung antar negara dan warga negar dalam segala aspek sebagaimana batasan pertama dari kutub interdependensi, maka PT dalam hal ini terimbas globalisasi dalam hal saling bergantungnya PT di suatu negara debgan PT di negara lain. Kebergantungan ini yang kemudian melahirkan adanya sekian banyaj bentuk kerjasama internasional PT dengan beberapa pihak yang dianggap mampu mengantarkan PT kepada kepentingan di dunia luas.

Ghafur (2009) dalam hal ini juga mengajukan beberapa pendapatnya tentang dampak globalisasi bagi PT, yaitu:

- PT dituntut paksa untuk merespons berbagai aspek yang muncul dari globalisasi dan dampaknya.

- PT dituntut untuk merespon globalisasi dengan menginternasionalisasi fungsi-fungsi akademik dan non akademiknya.

- PT didorong untuk masuk ke dalam struktur pasar yang keras dengan persaingan bebas dan terbuka.

- PT dituntut pro aktif untuk ambil bagian dari pertumbuhan masyarakat dunia berbasis jaringan dengan memperkuat daya dukung teknologi komunikasi dan informasi (ICT).

- Mengembangkan profesionalisme dan manajerialisme dengan memperkuat tata kelola PT yang baik (good university governance).

Sejalan dengan dampak globalisasi bagi PT, maka PT membutuhkan kemampuan lebih agar ia bisa melaksanakan kerjasama internasional sebagai salah satu jalan menuju WCU yang sudah menjadi satu kebutuhan yang tak terelakkan. Dalam hal ini jalan yang harus diwujudkan PT adalah dengan menerapkan strategi internasionalisasi PT.

\section{Internasionalisasi Perguruan Tinggi}

\section{Definisi Internasionalisasi PT}

Elliot (1999) dalam Ghofur (2009) mendefinisikan internasionalisasi PT sebagai "sebuah upaya sistematik dan berkelanjutan dari pemerintah untuk menjadikan lembaga-lembaga penyelenggara pendidikan tinggi lebih responsif terhadap tantangan globalisasi ekonomi dan masyarakat".

Kemudian masih dalam sumber yang sama, Knight mendefinisikan internasionalisasi PT sebagai proses pengintegrasian dimensi internasional dan interkultural ke dalam fungsi pengajaran, penelitian dan pelayanan dari sebuah institusi”. Dari definisi ini maka bisa dipahami: 
a) Internasionalisasi dan kerjasama internasional adalah proses yang dinamis dan perlu respon secara positif untuk pengembangan Iptek bagi kesejahteraan dan kemajuan peradaban umat manusia.

b) Pengintegrasian dan pemaduan dimensi-dimensi ingternasional adalah kata kunci yang penting untuk menjamin bahwa program, kebijakan dan prosedur yang berlaku pada sebuah PT harus mampu mengadopsi aspek-aspek internasional serta mendukunya keberlanjutan internasionalisasi.

\section{Pendekatan Internasionalisasi PT}

Untuk melakukan internasionalisasi PT, menurut Knight dalam Ghafur (2009) ada beberapa pendekatan yang biasa digunakan PT di dunia dalam melaksanakan internasionalisasi PT. Lebih jelasnya bisa dilihat dalam tabel berikut.

Tabel.1

Pendekatan Internasionalisasi PT

\begin{tabular}{|l|l|}
\hline \multicolumn{1}{|c|}{ Tipe Pendekatan } & \multicolumn{1}{c|}{ Fokus Kegiatan } \\
\hline Pendekatan aktivitas & - Pengembangan kurikulum \\
& internasional \\
& - Pertukaran mahasiswa \\
- Bantuan teknis & - Penjaringan mahasiswa asing \\
\hline Pendekatan kompetensi & - Peningkatan ketrampilan, sikap \\
& dan nilai yang mendukung \\
& program internasionalisasi pada \\
& mahasiswa, pengajar dan staf. \\
\hline Pendekatan etos & - Menekankan pada penciptaan \\
& kultur dan iklim kampus yang \\
& mendukung dan \\
& mempromosikan inisiatif \\
& internasional atau interkultural. \\
\hline Pendekatan proses & Integrasi atau pemaduan \\
& dimensi internasional dan \\
& interkultural ke dalam \\
& pengajaran, penelitian dan \\
& pelayanan melalui kebijakan \\
& prosedur dan kegiatan yang \\
& tepat. \\
\hline
\end{tabular}


Adapun strategi internasionalisasi PT yang biasa digunakan oleh berbagai PT di dunia, masih menurut Knight bisa dikelompokkan menjadi dua, yaitu:

Pertama. Strategi program, mencakup hal-hal yang terkait antara lain dengan kegiatan akademik, penelitian, hubungan eksternal dan pelayanan publik. Pada program akademik biasanya dilakukan programprogram seperti pertukaran mahasiswa, pengajaran bahasa asing, internasionalisasi kurikulum, penjaringan mahasiswa asing dan peningkatan kesempatan belajar di luar negeri bagi mahasiswa/staf pengajar. Selain progra, tersebut, program ini juga dilakukan dengan pembukaan kajian kewilayahan, program join/double degree, mengirim dan atau mengundang dosen tamu dari luar negeri.

Disamping itu, internasionalisasi dan kerjasama internasional juga bisa dilakukan melalui program kerja kolaboratif, seminar dan konferensi internasional, penerbitan artikel di jurnal-jurnal internasional, perjanjian penelitian internasional, serta pertukaran peneliti dan mahasiswa pascasarjana. Dalam konteks pelayanan publik dan hubungan eksternal, internasionalisasi PT tampil dalam berbagai program seperti kemitraan dengan lembaga swadaya masyarakat atau sektor swasta untuk menjalankan program-program layanan masyarakat, partisipasi dalam jaringan internasional, penyediaan layanan masyarakat dalam proyekproyek lintas batas negara, lintas kultural, dan pendataan serta jaringan alumni di mancanegara.

Kedua. Strategi organisasi dalam mengembangkan program internasionalisasi harus menyentuh aspek-aspek manajemen dan tata kelola, perangkat operasional, pengembangan SDM dan layanan pendukung. Strategi program harus menjamin bahwa dimensi internasional terlembagakan dengan baik melalui sumber daya manusia, kebijakan dan sistem administrasi. Untuk itu perlu pengintegrasian visi dan misi internasionalisasi ke dalam sistem perencanaan, penganggaran dan pengkajian mutu PT. Struktur organisasi yang tepat serta sistem komunikasi yang mendukung dan alokasi sumber daya yang memadai juga penting. Layanan pendukung bagi mahasiswa asing yang belajar di PT tersebut seperti layanan asrama, pelatihan bahasa, program orientasi dan sebagainya harus tersedia dengan baik dan tidak bisa diabaikan. Terakhir pula, tersedia SDM yang berkualitas yang dapat dilakukan melalui program-program penghargaan kepada staf, dukungan pada kegiatankegiatan staf di level internasional serta adanya sistem rekruitmen dan 
seleksi yang lebih terbuka dan tepat sehingga mampu menjaring orangorang yang mempunyai keahlian istimewa dengan reputasi internasional dan wawasan internasional.

\section{World Class University (WCU)}

WCU mempunyai pengertian yang berbeda-beda, baik target maupun kriteria penilaiannya. Saat ini beberapa institusi yang telah mantap dan diakui dunia sebagai lembaga pengakreditasi WCU antara lain: The Times Higher Education Suplement (THES) dengan situsnya di http://www.thes.co.uk; Academic Ranking of World Universities (ARWU) oleh Intitute of Higher Education, Shanghai Jiao Tong University, China yang dapat dilihat di situs http://www.arwu.org; Webometric (http://www.webometrics.info).

Adapun komponen yang harus ada dalam WCU menurut Hendarman, antara lain

1. World Reputation:

Third-party Endorsement (Pengesahan pihak ketiga)

Little room for engineering

World Ranking:

Time Higher Education Supplement

Shanghai Jiatong World Universities Ranking

Webometrics Ranking of World Universities

Global Ranking:

a. Time Higher Education Suplement
1) Peer review $(5,101)$
$40 \%$
2) Employee review $(1,471)$
$10 \%$
3) Student/Teacher ratio
$20 \%$
4) Citation index
$20 \%$
5) International Teachers
$5 \%$
6) International Students
$5 \%$

b. Shanghai Jiaotong Academic Ranking of world Universities

1) Alumni as Nobel Laureate $10 \%$

2) Faculty as Nobel Laureate 20\%

3) Highly-cited researchers 20\%

4) Articles in Nature and Science 20\%

5) Articles in SCI 20\%

6) Size 10\%

c. Webometrics Ranking of World Universities:

1) Web size 20\% 

2) Rich files
$15 \%$
3) Scholar (Google)
$15 \%$
4) Visibility (Link)
$50 \%$

\section{Prominents Graduates}

1) Celebrities of national culture

2) Community leaders

3) International figures

3. Research Performance

1) Research output:

a) Research assessment Exercises

b) Dominance of Anglo-saxon research culture

2) Strategic capacity building

a) Strategic of resources on selected areas

b) Concentration of talents

\section{International participation}

Kriteria WCU yang terkait dengan citra internasional dengan indikator: jumlah dosen dan mahasiswa internasional, kualitas riset internasional, angka serapan alumni dan kualitas pengajaran.

Hampir senada dengan pendapat Hendarman adalah pendapat Prof.Dr.Tridoyo Kusumastono. Menurutnya ada beberapa kriteria yang digunakan untuk mengidentifikasi apakah suatu universitas tertentu masuk ke WCU, yaitu:

a) $40 \%$ tenaga pendidik bergelar Ph.D

b) Publikasi internasional 2 paper/staf/tahun

c) Jumah mahasiswa pasca $40 \%$ dari total populasi mahasiswa (student body)

d) Anggaran riset minimal US\$1300/staf/tahun

e) Jumlah mahasiswa asing lebih dari $20 \%$

f) ICT $10 \mathrm{~kb} /$ mahasiswa (http://tridoyo.blogspot.com)

Dengan beberapa kriteria yang diajukan oleh beberapa lembaga pemeringkatan PT kelas dunia, maka ada beberapa PT di Indonesia yang memiliki potensi besar menjadi WCU. Berdasarkan data THE tahun 2008 ada 3 PT Indonesia yang masuk 500 besar, yaitu UI (peringak 287), ITB (315), UGM (316). Sementara Universitas Airlangga,IPB, Universitas Brawijaya Universitas Diponegoro masuk 1000 besar.

Kemudian berdasarkan Webometrics untuk kategori Asia, terdapat 21 PT Indonesia yang masuk peringkat 100 besar, yaitu Universitas 
Gunadharma (peringkat 4), IPB (8), Universitas Brawijaya (9), Universitas Airlangga (11), dan Undip (15).

Untuk bisa menuju WCU, menurut Prof. Kai-Ming, seorang ahli kebijakan pendidikan dan konsultan UNESCO dan World Bank, maka PT harus memiliki empat hal berikut: 1) reputasi internasional, prestasi penelitian, lulusan yang terkemuka, dan partisipasi internasional. Kalau empat hal ini belium terpenuhi, jangan bermimpi dulu menjadi universitas kelas dunia. Selain itu, untuk membangun universitas kelas dunia, ada beberapa prasyarat dan komitmen yang tidak bisa ditawar, yaitu: 1) pembangunan pendidikan tinggi sebagai prioritas, 2) harus memperhatikan sumber daya, dan komitmen yang tidak bisa ditawar, yaitu: 1) pembangunan pendidikan tinggi sebagai prioritas, 2) harus memperhatikan sumber daya,) sudah memiliki identifikasi institusi, 4) rekruitmen akademisi, 5) mengembangkan sumber daya, dan 6) melakukan reformasi tata kelola.

Dengan mengambil data tahun 2005 saja, prof. Kai-Ming mencontohkan bagaimana negara-negara Asia yang telah menjadikan pembangunan pendidikan tinggi sebagai prioritas, misalnya Korea Selatan, rasio partisipasi pendidikan tingginya sudah mencapai $84 \%$, Thaiwan sudah $82 \%$, Jepang $76,2 \%$, Singapura $81 \%$ dari $15 \%$ pada tahuhj 1990 -an awal dan Honglong sendiri sudah $67 \%$ dari 30\% pada tahun 2002 .

Di luar itu semua, PT harus memenuhi standar/benchmark mutu internasional. Dalam hal ini Jacksin and Lund (2000) menyampaikan beberapa benchmarking pendidikan tinggi, yaitu:

1) Benchmarking to improve the quality of educational practice and regulate standard: Benvhamrking educational processes and outcomes, the learning environment, to improve departemental system for managing quality and standar, the student experience, the outcomes of learning, key skills using national standard.

2) Benchmarking to improve the quality of administrative and bussiness processes and services to support HE: student recruitment, facilities and estates management, the learning instructure: library and information services.

3) Benchmarking in other HE system and trasnational benchmarking.

Secara praktis kemudian benchmarking ini berkembang menjadi sebuah pembakuan standar mutu PT internasional yang dilakukan oleh beberapa organisasi baik tingkat regional hingga internasional. Pembakuan 
standar mutu ini digunakan untuk melakukan akreditasi lembaga dan penjaminan mutu.

Berikut ditampilkan organisasi penjaminan mutu pendidikan PT baik regional maupun internasional.

Tabel.2

Organisasi Penjaminan Mutu PT

\begin{tabular}{|c|c|c|}
\hline Nama Organisasi & Wilayah Kerja & Keterangan \\
\hline $\begin{array}{l}\text { Asean University } \\
\text { Network-Quality } \\
\text { Assurance (AUN-QA) }\end{array}$ & ASEAN & \\
\hline$C H E A$ & $\begin{array}{l}\text { Amerika serikat Dan } \\
\text { Kanada }\end{array}$ & \\
\hline $\begin{array}{l}\text { The European Association } \\
\text { for Quality Assurace In } \\
\text { Higher } \\
\text { (ENQA) Education }\end{array}$ & Uni Eropa & \\
\hline $\begin{array}{l}\text { External Quality Review } \\
\text { (EQR) }\end{array}$ & Internasional & \\
\hline $\begin{array}{l}\text { International Quality } \\
\text { Review Process (IQRP) }\end{array}$ & Internasional & \\
\hline $\begin{array}{l}\text { The Interbational } \\
\text { Network of Quality } \\
\text { Assurance Agencies in } \\
\text { Higher education } \\
\text { (INQAAHE) }\end{array}$ & Internasional & $\begin{array}{l}\text { Lembaga penghimpun } \\
\text { lembaga-lembaga } \\
\text { penjaminan mutu di } \\
\text { dunia. BAN PT } \\
\text { termasuk anggotanya. }\end{array}$ \\
\hline
\end{tabular}

\section{E. Analisis Kebijakan Internasionalisasi Perguruan Tinggi Di Indonesia Menuju World Class University.}

Internasionalisasi PT di Indonesia merujuk kepada UU Sisdiknas tahun 2003 pasal 64 dan 65 yang dijabarkan lebih dulu dalam PP.N0 60/1990 tentang Perguruan Tinggi, PP N0.61/1999 tentang Badan Hukum PT (Ghafur, 2009). Lebih lanjut dikatakan bahwa ketentuan yang mengatur tentang pendidikan lintas batas negara dan kerjasama internasional dalam PP ini, ada pada pasal 125, 129 dan 130. Demikian juga Mendiknas dan dirjen Dikti telah mengeluarkan Surat keputusan yang memberi petunjuk dan arahan teknis tentang bentuk-bentuk kegiatan dan kerjasama luar negeri yang dapat dilakukan oleh PT Indonesia dengan PT 
atau lembaga lain di luar negeri. Peraturan yang menjadi rujukan antara lain:

1. SK Mendikbud N0. 264/U/1999 tentang Kerjasama PT du Indonesia dengan PT/lembaga lain di Luar negeri.

2. SK Dirjen Dikti N0.61/Dikti/Kep/2000 tentang Petunjuk Pelaksanaannya.

Adapun ketentuan tentang peraturan yang terkait dengan kerjasama internasional dan pendidikan lintas batas negara menurut UU Sisdiknas 2003 bisa disimak dalam tabel berikut.

Tabel.3

Internasionalisasi Pendidikan menurut UU Sisdiknas

\begin{tabular}{|c|c|c|c|}
\hline $\begin{array}{l}\text { Bentuk } \\
\text { Lembaga }\end{array}$ & Bentuk Sistem & $\begin{array}{l}\text { Ketentuan } \\
\text { Aturan }\end{array}$ & Ketentuan Aturan \\
\hline $\begin{array}{l}\text { Lembaga } \\
\text { pendidikan } \\
\text { yang didirikan } \\
\text { oleh } \\
\text { Perwakilan } \\
\text { Negara Asing } \\
\text { dalam NKRI }\end{array}$ & $\begin{array}{l}\text { Menggunakan } \\
\text { sistem negara } \\
\text { bersangkutan }\end{array}$ & $\begin{array}{l}\text { Peraturan yang } \\
\text { berlaku di } \\
\text { negara } \\
\text { bersangkutan }\end{array}$ & $\begin{array}{l}\text { Diperuntukkan } \\
\text { bagi WNA }\end{array}$ \\
\hline $\begin{array}{l}\text { Lembaga } \\
\text { Pendidikan } \\
\text { Asing dalam } \\
\text { NKRI }\end{array}$ & $\begin{array}{l}\text { Menggunakan } \\
\text { sistem } \\
\text { pendidikan } \\
\text { nasional } \\
\text { Indonesia } \\
\text { (Sisdiknas) }\end{array}$ & \begin{tabular}{l}
\multicolumn{2}{l}{ Menggunakan } \\
Peraturan per- \\
UU-an \\
Indonesia
\end{tabular} & $\begin{array}{l}\text { Wajib } \\
\text { memberikan } \\
\text { pengajaran } \\
\text { pendidikan agama } \\
\text { dan } \\
\text { kewarganegaraan } \\
\text { bagi siswa SD s/d } \\
\text { SLTA yang WNI. } \\
\text { Bekerjasama } \\
\text { dengan lembaga } \\
\text { pendidikan } \\
\text { Indonesia. } \\
\text { Mengikutsertakan } \\
\text { pendidik dan } \\
\text { pengelola WNI }\end{array}$ \\
\hline $\begin{array}{l}\text { Lembaga } \\
\text { pendidikan } \\
\text { Indonesia }\end{array}$ & $\begin{array}{l}\text { Menggunakan } \\
\text { sistem } \\
\text { pendidikan }\end{array}$ & $\begin{array}{l}\text { Menggunakan } \\
\text { peraturan per- } \\
\text { UU-an }\end{array}$ & $\begin{array}{l}\text { Terbuka bagi } \\
\text { WNA dan WNI. }\end{array}$ \\
\hline
\end{tabular}




\begin{tabular}{|l|l|l|l|}
\hline negara lain, & Indonesia & \\
seperti & & \\
jenjang, & & \\
kurikulum, & & \\
sistem & & \\
penilaian dsb. & & \\
\hline
\end{tabular}

Dari peraturan tersebut dapat ditangkap pikiran tentang kategori kerjasama P'T, yaitu:

1) Kerjasama pendirian PT, dalam bentuk patungan antara pihak luar negeri dengan mitra Indonesia. Untuk kerjasama ini berlaku ketentuan sebagai berikut: a) mengikuti ketentuan Sisdiknas, b) memenuhi seluruh persyaratan dan tatacara pendirian PT yang berlaku di Indonesia.

2) Kerjasama kegiatan akademik bersyarat, yaitu bila kerjasama yang dilakukan berbentuk: a) kontrak manajemen, b) program kembaran (twinning program), c) program pemindahan kredit yang diperoleh (credit transfer). Untuk ketiga jenis kerjasama ini, berlaku persyaratan bahwa program studi dari PT luar negeri yang telah terakreditasi di negeri asalnya.

3) Kerjasama kegiatan akademik yang terbuka dan tanpa syarat, yaitu bila kerjasama berbentuk: a) tukar menukar dosen dan mahasiswa dalam bidang akademik, b) pemanfaatan bersama sumber daya dalam kegiatan akademik, c) penerbitan bersama karya ilmiah, d) penyelenggaraan bersama seminar atau kegiatan ilmiah lainnya dan e) bentuk-bentuk lain yang dianggap perlu (Ghafur, 2009).

Selain aturan-aturan tersebut, Indonesia memiliki lembaga-lembaga pendukung internasionalisasi PT yang bekerja dalam kerangka dua pendekatan, yaitu 1) koordinasi isi kerjasama dapat dilakukan dengan berkoordinasi pada departemen/kementrian terkait. Kerjasama ini bisa berubah dan berpindah dari satu departemen ke departemen lain sesuai bidang kerjanya, 2) koordinasi struktural dengan departemen/kementrian terkait.

Terkait dengan pendekatan kedua, di Indonesia ada dua departemen yang melakukan kerjasama PT dengan luar negeri, yaitu Departemen/Kementrian Pendidikan Nasional dan Departemen Luar Negeri. Di mana secara internal, koordinasi dilakukan oleh Direktorat Jenderal Pendidikan Tinggi dan Biro Perencanaan dan Kerjasama Luar 
Negeri, Kemendiknas, dengan Itjen Hukum dan Perjanjian Internasional dan Ditjen Informasi dan Diplomasi Publik dari Kementrian Luar Negeri.

Kemudian secara khusus untuk memperkuat dan menghubungkan kerjasama internasional bidang pendidikan dan kebudayaan dengan negara lain, saat ini Indonesia telah memiliki 13 atase pendidikan, yaitu AS, Australia, Belanda, Jerman, Inggris, Perancis, Malaysia, Mesir, Saudi Arabia, Thailand, Philipina, Jepang dan Papua New Guini. Selanjutnya untuk peningkatan kerjasama, maka pada tahun 2002 Itjen Dikti mendirikan Pusat Jaringan Kerjasama Luar Negeri Perguruan Tinggi (PJKLN) yang mengkoordinasikan program Asia, Eropa, AS dan Kanada, Australia, Jepang dan berbagai program dan kegiatan yang bersifat multikultural.

Di luar departemen pemerintah, maka muncul lembaga swasta masyarakat non pemerintah (Non Government Organizational/NGO) yang turut aktif menyelenggarakan kerjasama internasional PT, diantaranya: Ford Foundation (FF), The Asia Foundation (TAF), Rockefeller Foundation (RF), Smithsonian Institute (SI), East-West Center (EWC), Fullbright Foundation dan sebagainya.

Secara normatif, Indonesia sudah mengeluarkan produk kebijakan atas kemungkinan dilakukannya internasionalisasi PT. Namun secara praktis, berdasarkan hasil penelitian yang dilakukan oleh Ghafur (2009), PT di Indonesia, khususnya yang BHMN yang sudah melaksanakan internasionalisasi PT, biasanya mengambil bentuk kegiatannya sebagai berikut:

Pertama. Kegiatan yang berbasis pada struktur yang sudah ada, dengan memberi dimensi internasionalisasi dari dalam (internationalization within) terhadap kurikulum, proses pebelajaran dan sebagainya. Bentuk kegiatan ini adalah internasionalisasi berperangkat struktur lunak (soft structure activities).

Kedua. Kegiatan kongkrit berbasis hubungan kerjasama antara struktur internal dengan pihak ekseternal/asing. Kegiatan ini disebut hard structure activities, yang bentuk kegiatannya antara lain:

a) Pengiriman dosen untuk studi lanjut ke luar negeri dan kehadiran dosen dan peneliti asing di PT setempat.

b) Pengiriman mahasiswa untuk kunjungan keluar negeri.

c) Mobilitas internasional staf pengajar, peneliti dan pimpinan PT, baik yang akademik maupun yang non akademik.

d) Keanggotaan dalam berbagai forum kerjasama dan asosiasi internasional seperti ASEAN University Network (AUN), 
Association of Pasific Rim Universities (APRU), Association of Southeast Asia Institution of Higher Learning (ASAIHL), ASEAN-Eurepeon Academic University Network (ASEAN-Uninet), Southeast Asian Minister of The Islamic World (FUIW) dan sebagainya.

e) Peluang dan pemanfaatan dana internasional, seperti Asia link, Marie Curie International fellowship, FP-6, tematic Priorities of research, International Cooperation Action (INCO), United States Institute of Peace (USIP), Toyota Foundation, Japan Foundation Research Fund (JFRF), Tokyo Foundation Research Grant dan lain-lain.

f) Perjanjian internasional dengan lembaga, organisasi atau PT luar negeri,. Baik akademik maupun non akademik dengan Memorandum of Understanding (MoU) dan ditinfak lanjuti dengan Letter of implementation (LoI)

g) Publikasi Makalah di berbagai jurnal internasional atau kerjasama penerbitan dengan lembaga-lembaga internasional.

\section{F. Penutup}

Dalam rangka merespon tuntutan globalisasi, maka PT perlu melakukan sekian banyak perubahan dalam pengelolaan kelembagaannya jika tidak ingin tergilas arus kompetisi yang sudah sedemikian tinggi. Kompetisi tidak hanya antar PT di negeri sendiri, tapi juga dengan PT negara lain. Salah satu strategi yang seyogyanya dijalankan adalah strategi internasionalisasi PT. Strategi inilah yang akan mengantarkan PT masuk dalam WCU.

\section{Referensi}

Ahmadi, Abu.(2005). Integrasi Pendidikan Umum dan Pendidikan Agama

Ghafur, A. Hanief Saha.(2009). Manajemen Mutu, Penjaminan Dan Internasionalisasi Perguruan Tinggi Di Indonesia. Jakarta: UI Press Khufad, Ahmad.(2009). Globalisasi. Materi Perkuliahna SPS UPI Bandung Nines, Peter and Hellsten, Meeri.(2005). Internationalizing Higher Education. Critical Exploration of Pedagogy and Policy. Netherlands: Springer

Sufyarma, M. (2004). Kapita Selekta Manajemen Pendidikan. Bandung: Alfabeta

Salehi, Sayyid Reza Amiri.(2009). Strategi Untuk Menciptakan Enterpreneur University dalam European Journal of Social Sciences, Volume 1, Nomor 3 tahun 2009. 